\title{
USING INDICATOR KRIGING AND GIS FOR MAPPING PHOSPHATE GRADES AT QURAYAT DISTRICT, EGYPT
}

\author{
S. S. Ahmed, M. R. El Tahlawi, M. Z. Rashad and H. A. Saleem \\ Mining and Metallurgical Engineering Department, Faculty of \\ Engineering, Assiut University, Assiut, 71518, EGYPT. \\ Email: dr sameh mining04@yahoo.com Fax: +20088 2332553
}

(Received September 1, 2006 Accepted September 25, 2006)

Understanding the spatial distribution of Phosphate ores, particularly $\mathrm{P}_{2} \mathrm{O}_{5} \%$ can aid mining engineers in identifying the areas that have high and low values of $\mathrm{P}_{2} \mathrm{O}_{5} \%$ in order to manage the extraction scheme. Most studies that have been carried out in Egyptian phosphate ores, focused on calculations of average $\mathrm{P}_{2} \mathrm{O}_{5} \%$, average thickness, and total tonnage and seldom concern with spatial variability and mapping of $\mathrm{P}_{2} \mathrm{O}_{5} \%$. This paper introduces indicator kriging and its uses (for the first time in Egypt) in mapping phosphate grades, and illustrates how the kriging results can be interpreted easily when they are integrated with other geological and mining data using suitable Geographic Information System. Egyptian Mineral Resources Authority (EMRA) provided data for Qurayat area. GIS software (ARC/GIS 9.0) was used to post the locations and geological maps of samples and study area, and the integration of IK and GIS allowed using creative colours to delineate the relative magnitudes of the measurements recorded at these locations, so a better understanding of the ore distribution has been much-admired.

KEYWORDS: Indicator kriging, Ordinary kriging, El-Mahamid, $\mathrm{P}_{2} \mathrm{O}_{5} \%$, GIS

\section{INTRODUCTION}

Phosphate ore, one of the principal mineral products of Egypt, is widely distributed in four main localities that are the Eastern Desert, Sinai, the Nile Valley, and the Western Desert. The Nile valley phosphorite deposit is a part of the vast upper Cretaceous marine phosphorite basin. The eastern Mahamid region consists of five prospected areas that are Sharawna, Oweiniya, Mussattah Yassin, Hagaria, and Qurayat [1].

Phosphate rocks are used extensively, mainly as a source of phosphorus for fertilizers, and for manufacture of phosphoric acid and other chemicals [2]. The phosphate rock can be classified according to its grade as follows: poor grade $\mathrm{P}_{2} \mathrm{O}_{5} \%$ ranges from 15 to 22 , medium grade $\mathrm{P}_{2} \mathrm{O}_{5} \%$ ranges from 22 to 27 , and rich grade $\mathrm{P}_{2} \mathrm{O}_{5} \%$ greater than 27 [3]. Thus, identifying the geographic distribution of $\mathrm{P}_{2} \mathrm{O}_{5} \%$ is critical for mining engineers and would help the mining designer or decision maker to select the mining method for extraction and control the production. 


\section{APPLICATIONS OF KRIGING TECHNIQUE}

Over the past four decades, kriging technique has proved superiority as for estimating reserves in most types of mineral deposits, especially gold and rich minerals. Its use has been extended to other fields such as environmental science, hydrogeology, agriculture and fisheries [4].

The technique is known, so far, as the best estimation technique, it gives better estimations for the relative ore reserves. Except when the distance between the drill holes is very large, the technique of kriging could not give satisfactory results, and the estimated variance for the kriged value would be highly unacceptable [5].

According to different requirements of different problems, one refers to simple kriging $(S K)$ when a known mean value (or mean surface, if local searching neighbourhood) is used as input to the model; ordinary kriging (OK) assumes a constant, but unknown mean and estimates the mean value as a constant in the searching neighbourhood. Universal kriging (UK) models local means as a sum of low order polynomial functions of the spatial coordinates and then estimates the coefficients in this model. It should be mentioned that, simple, ordinary and universal kriging are optimal for Gaussian data only [6].

The following section demonstrates some of the most recent applications of kriging in mining and some other related fields.

Local linear regression (LR), inverse distance weighting (IDW), ordinary kriging, simple kriging with a locally varying mean (SKlm) and kriging with an external drift were used to predict $\mathrm{NO}_{2}$ diffusion from point data, collected as part of the United Kingdom, SKlm provided the most accurate predictions based on the summary statistics of prediction errors from cross-validation [7]. Kriging method was used to interpolate the content of feldspar in the entire granite deposit in order to characterize the saleable feldspar in a granite deposit, and used to calculate the quantity of feldspar [8]. The results of inverse distance, ordinary kriging and median indicator kriging estimation were compared in the iron ore deposit that includes examination of local estimates and data distributions and showed that, the kriging methods have improved the estimation compared with the inverse distance method, in the block data distributions and the pattern of local estimates [9]. Ordinary kriging and lognormal kriging were used to map the spatial patterns of heavy metals and disjunctive kriging was used to quantify the probability of heavy metal concentrations higher than their guide value, while Co-kriging method was used to minimize the sampling density for $\mathrm{Cu}, \mathrm{Zn}$ and $\mathrm{Cr}$ [10]. Universal kriging was used to create the probabilistic map of carbon monoxide concentration (ppm) as one of air pollutants [11]. Universal kriging and disjunctive Kriging were used to map the soil contamination and the probability of exceeding of the upper permissible level [6]. The median indicator kriging method is considered to provide a better way of estimating an element with a bimodal or strongly skewed distribution. Outlying assay values have less influence when using the median indicator kriging method [9].

An example of integrated kriging technique and GIS is found in the work done by Diodato and Ceccarelli (2004) [12], they used multivariate geostatistical technique of indicator kriging to detect and classify macro zones according to their tendency to soil degradation. Geographical Information System (GIS) is used to delineate the areas suited to soil degradation maps. 
Geographical Information System technology was used as a data management platform and three different interpolation techniques; spline, inverse distance weighted and kriging were used to visualize the spatial distribution of rainfall data in space and time in order to estimate storm characteristics from rainfall observations obtained by any number of rain gages [13]. A combination of geologic and GIS models has been used to analyze the sample data to estimate tonnages and qualities of the coal beds [14].

The main objective of this paper is to interpolate $\mathrm{P}_{2} \mathrm{O}_{5} \%$ at an un-sampled location based on surrounding measurements, and then plot these magnitudes on prediction maps to familiarize mining engineers or decision makers. In order to do this, indicator kriging was used for grade estimation at the mining area of Qurayat, and GIS was used to enhance the characterisation and display of resulting maps together with the other data.

\section{PRINCIPALS AND METHODOLOGY}

It is beyond the scope of this paper to explain the different kriging techniques however; the following are the main principles of the two types that are used in this research.

\section{Ordinary Kriging (OK)}

Ordinary kriging assumes that the mean is known or that the data have been de-trended. The estimation variance is:

$$
\begin{aligned}
\sigma_{E}^{2} & =\boldsymbol{E}\left[\left(\boldsymbol{Z}^{*}\left(\boldsymbol{X}_{\mathrm{o}}\right)-\boldsymbol{Z}\left(\boldsymbol{X}_{\mathrm{o}}\right)\right)^{2}\right] \\
& =-\gamma\left(X_{0}-X_{0}\right)-\sum_{\alpha=1}^{n} \sum_{\beta=1}^{n} \omega_{\alpha} \omega_{\beta} \gamma\left(X_{\alpha}-X_{\beta}\right)+2 \sum_{\alpha=1}^{n} \omega_{\alpha} \gamma\left(X_{\alpha}-X_{0}\right)
\end{aligned}
$$

Where, $\sigma_{E}^{2}$ is the estimation variance, $\mathrm{E}$ is the estimation error, $\mathrm{Z}^{*}\left(\mathrm{X}_{0}\right)$ is the estimated value at location $\mathrm{X}_{0}, \mathrm{Z}\left(\mathrm{X}_{0}\right)$ is the true value, $\gamma\left(\mathrm{X}_{0}-\mathrm{X}_{0}\right)$ is the variogram, $\left(\omega_{\alpha} \& \omega_{\beta}\right)$ are the weights and $\left(X_{\alpha} \& X_{\beta}\right)$ are the neighboured samples.

By minimizing the estimation variance with the constraint on the weights, the ordinary kriging system is obtained:

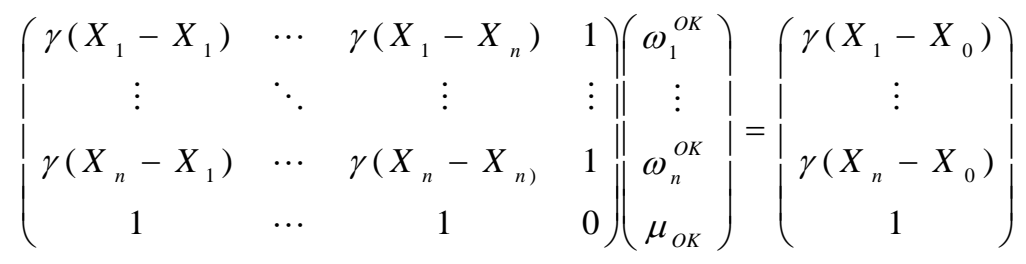

Where the $\omega_{\alpha}^{O K}$ are weights to be assigned to the data values and where $\mu_{O K}$ is the Lagrange parameter. The left hand side of the system describes the dissimilarities between the data points, while the right hand shows the dissimilarities between each data point and the estimation point $\mathrm{X}_{0}$.

Performing the matrix multiplication, the ordinary kriging system can be rewritten in the form: 


$$
\left\{\begin{array}{l}
\sum_{\beta=1}^{n} \omega_{\beta}^{O K} \gamma\left(X_{\alpha}-X_{\beta}\right)+\mu_{O K}=\gamma\left(X_{\alpha}-X_{0}\right) \text { For } \alpha=1, \ldots ., n \\
\sum_{\beta=1}^{n} \omega_{\beta}^{O K}=1
\end{array}\right.
$$

The estimation variance of ordinary kriging is

$$
\sigma_{O K}^{2}=-\mu_{O K}-\gamma\left(X_{0}-X_{0}\right)+2 \sum_{\alpha=1}^{n} \omega_{\alpha}^{O K} \gamma\left(X_{\alpha}-X_{0}\right)
$$

Ordinary kriging is an exact interpolator in the sense that if $\mathrm{X}_{0}$ is identical with a data location then the estimated value is identical with the data value at that point

$$
Z^{*}\left(X_{0}\right)=Z\left(X_{\alpha}\right) \quad \text { if } \mathrm{X}_{0}=\mathrm{X} \alpha
$$

(including $\mu_{O K}$ ) equal to zero is a solution of the system. As the left hand matrix is not singular, this is the only solution [15].

\section{Indicator Kriging (IK)}

IK uses thresholds to create binary data ( 0 or 1 values), and then uses ordinary kriging to make spatial predictions based on the indicator data. Predictions using indicator kriging are interpreted as the probability of exceeding the specified threshold [6]. IK works as follows.

A series of cut off values (COV) are chosen which are spread through the data values so that they cut the data into a number of groups with ascending values. For example, if the data cover a range of 200 to 1000 , COV may be set at 300, 400, 500, $600,700,800$ and 900 , to give 8 groups. The COV need not rise in equal increments. Taking the lowest COV, all data above this receive an indicator value of zero, and those with values equal to or less than the COV receive indicator value of unity, viz.:

$$
\begin{array}{ll}
Z_{I K}(x)=1 & \text { if } \mathrm{Z}(\mathrm{x}) \leq \mathrm{COV}_{\mathrm{k}} \\
\mathrm{Z}_{\mathrm{IK}}(\mathrm{x})=0 & \text { if } \mathrm{Z}(\mathrm{x})>\mathrm{COV}_{\mathrm{k}}
\end{array}
$$

Where: $\mathrm{Z}_{\mathrm{IK}}(\mathrm{x})$ is the indicator value of the raw data value $\mathrm{Z}(\mathrm{x})$ at location $\mathrm{x}$.

IK is obviously useful for tackling the same problem as Lognormal Kriging (LK) (that is used with highly skewed data), i.e. where the occasional high value occurs in a small set of data [16].

\section{STUDY AREA}

The study area is Qurayat locality (Figure 1) which is one of five regions in Eastern Mahamid area. This area lies along the right bank of the Nile, to the south of Qena and Luxor, between towns of Esna and Idfu. It is bounded by coordinates latitudes $\left(25^{\circ} 15^{\prime}\right.$ and $\left.25^{\circ} 05^{\prime} \mathrm{N}\right)$ and longitudes $\left(33^{\circ} 32^{\prime}\right.$ and $\left.33^{\circ} 00^{\prime} \mathrm{E}\right)$. Qurayat locality has an area about $26.52 \mathrm{~km}^{2}$. El-Mahamid deposit is mainly confined to the Upper Cretaceous marine sediments distributed in both the Eastern and Western sides 
of the Nile Valley. The overlaying Paleocene sediments form the topographic highs, which limit the eastern area from the north and north-west. The Upper Cretaceous sediments are subdivided into two formations, which are, from bottom to top, the Duwi and Dakhla Formations.

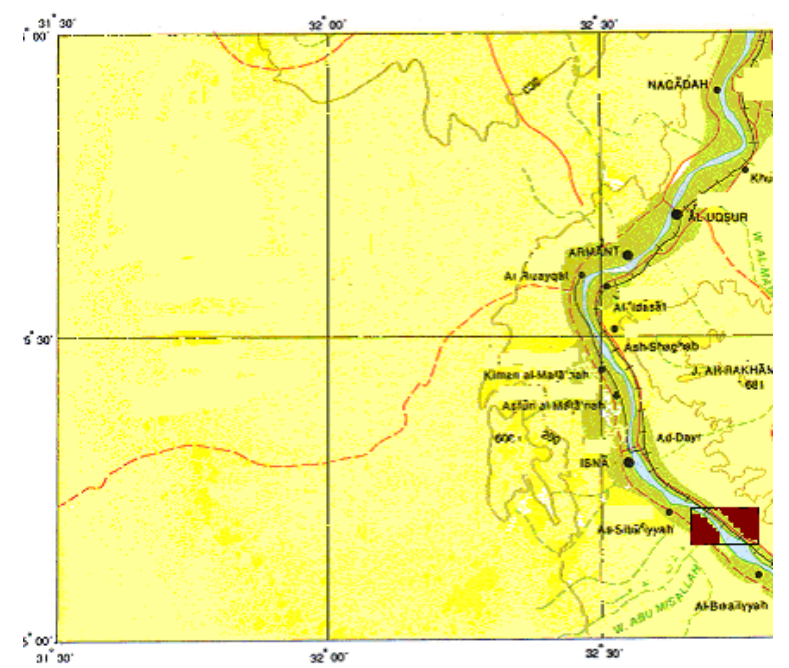

Location of El-Mahamid district

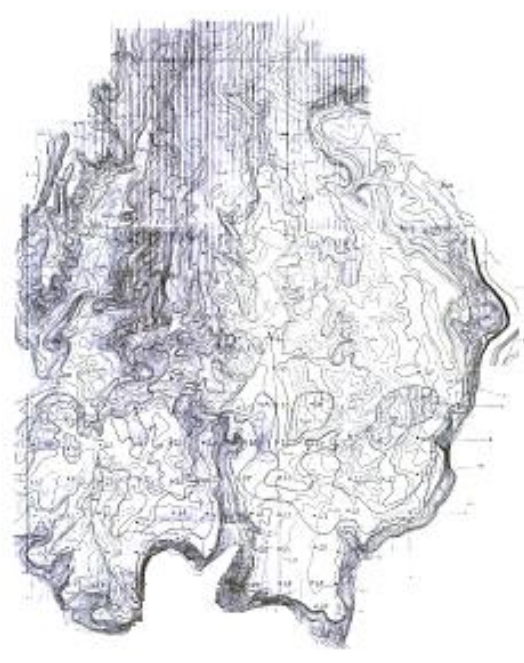

El Qurayat

Figure 1: Location map of the study area at Qurayat, Egypt [17].

The Duwi Formation (Companion stage) is lithologically subdivided into two sub-formations namely, the Variegated Shales sub-formation $\left(\mathrm{Cr}_{2} \mathrm{VS}\right)$ and the phosphorite sub-formation $\left(\mathrm{Cr}_{2} \mathrm{Ph}\right)$. The important sub-formation is the last one $\left(\mathrm{Cr}_{2} \mathrm{Ph}\right)$, which is subdivided into three members, namely the lower productive carbonate-phosphorite member $\left(\mathrm{Cr}_{2} \mathrm{Ph}_{1}\right)$, middle phosphorite-clayey member $\left(\mathrm{Cr}_{2} \mathrm{Ph}_{2}\right)$ and upper phosphorite-clayey member $\left(\mathrm{Cr}_{2} \mathrm{Ph}_{3}\right)$. The lower productive carbonatephosphorite member $\left(\mathrm{Cr}_{2} \mathrm{Ph}_{1}\right)$, which includes commercial phosphorite beds, is the main object of the investigations carried out in the area. The Dakhla Formation (Maestrichtian stage) does not contain phosphorite intercalation or poor phosphatic marl and limestone [1].

\section{RESULTS AND DISCUSSIONS}

Seventy-five samples were collected from different locations in Qurayat area, in order to study and map the spatial distribution of $\mathrm{P}_{2} \mathrm{O}_{5} \%, \mathrm{X}, \mathrm{Y}$ and $\mathrm{P}_{2} \mathrm{O}_{5} \%$, were recorded at each sampling point. Figure 2 shows the positions of the selected samples.

\section{Descriptive Statistics}

The original data of the sampling points is presented in Figure 3(a), while Figure 3(b) illustrates the samples upon removing two extreme values (W-18 and Q-18). Those points were reported with zero $\mathrm{P}_{2} \mathrm{O}_{5} \%$ values. Such samples might mislead the kriging results and should be excluded, thus, all the next calculations were made using 73 samples only. 


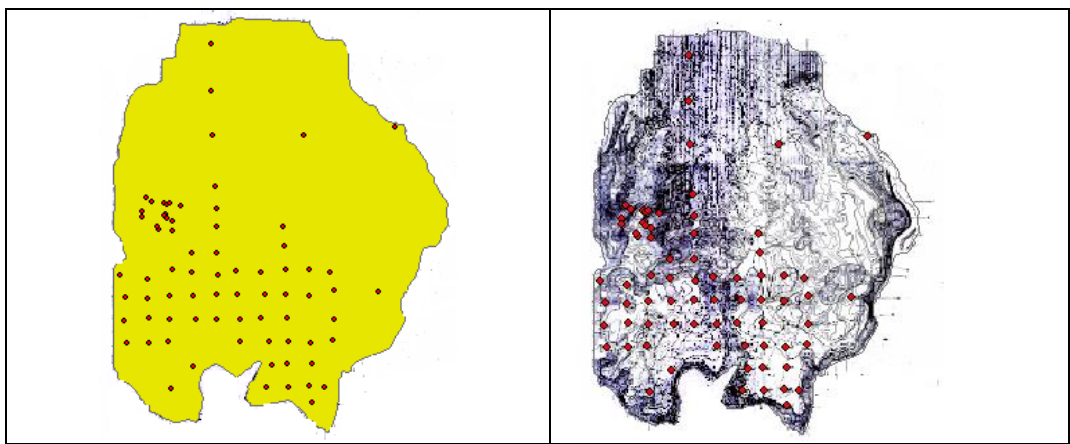

Figure 2: Distribution of the 75 sampling points in Qurayat area.

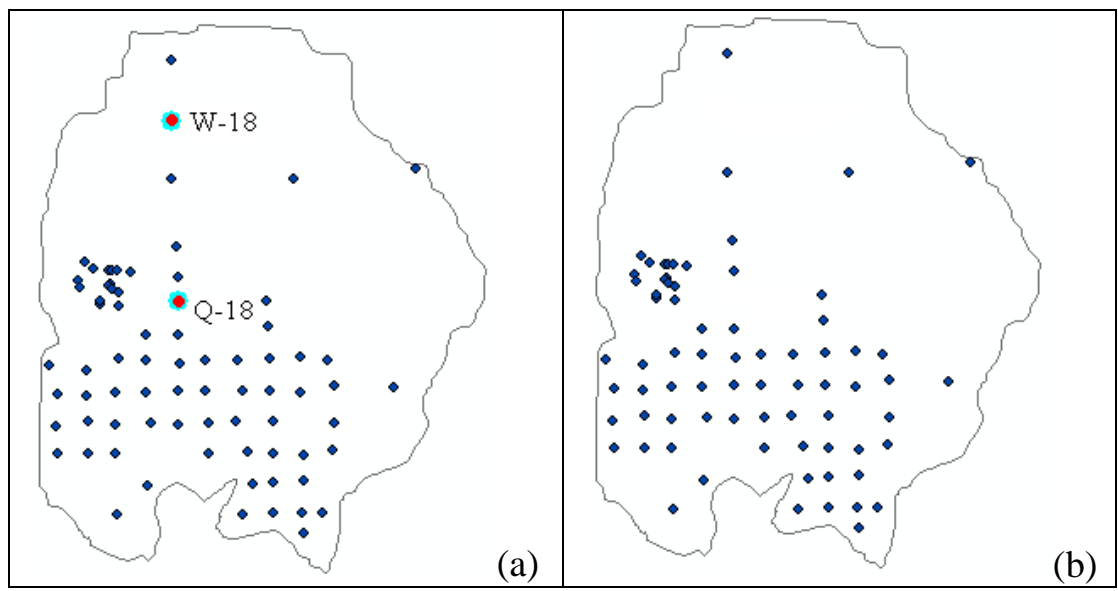

Figure 3: Sampling point before/after cancel of W-18 and Q-18.

The histogram of $\mathrm{P}_{2} \mathrm{O}_{5} \%$ data has been performed and Figure 4 shows the results where a distribution that is negatively skewed. Q-Q plot illustrates that data is not normal distribution, thus the most appropriate system of interpolation is Indicator Kriging (IK).

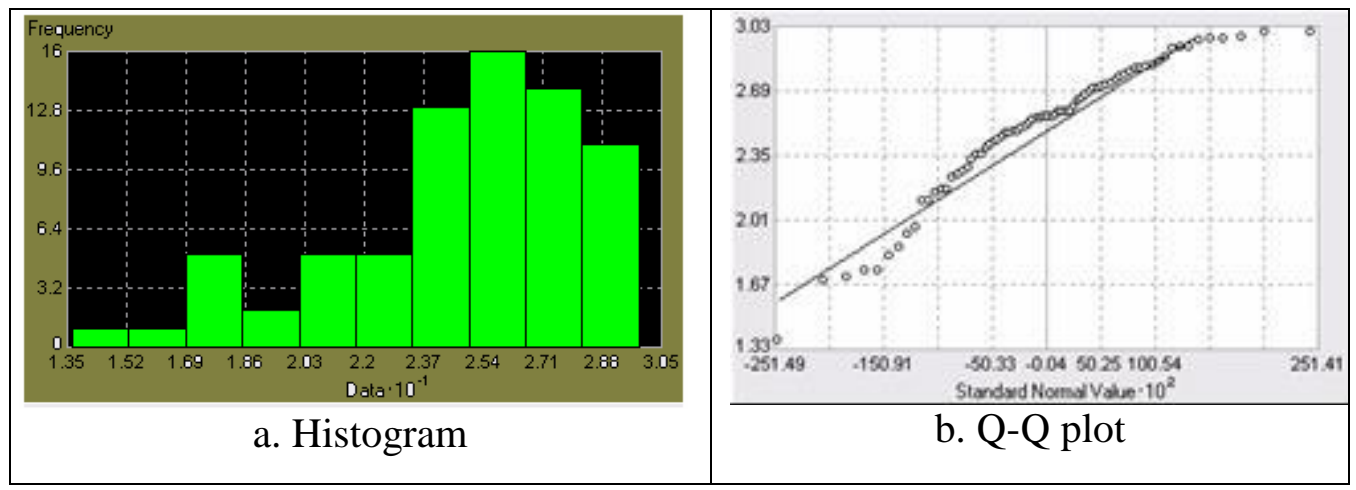

Figure 4: The distribution of $\mathrm{P}_{2} \mathrm{O}_{5} \%$ data. 
Table 1 gives the summary statistics of the data sets for $\mathrm{P}_{2} \mathrm{O}_{5} \%$, in both cases, using the overall data and the decided 73 points.

Table 1: Summary statistics of $\mathrm{P}_{2} \mathrm{O}_{5} \%$ in Qurayat area.

\begin{tabular}{|l|c|c|c|c|c|c|c|c|}
\hline $\begin{array}{l}\text { Statistical } \\
\text { Parameter }\end{array}$ & Cont. & Min. & Max. & Mean & $\begin{array}{l}\text { Std. } \\
\text { Dev. }\end{array}$ & Skew. & Kurtosis & Median \\
\hline Raw data & 75 & 0 & 29.85 & 24.11 & 5.36 & -2.57 & 11.77 & 25.35 \\
\hline Treated Data & 73 & 13.65 & 29.85 & 24.77 & 3.60 & -0.89 & 3.42 & 25.45 \\
\hline
\end{tabular}

\section{Geostatistical Analysis}

The first step in geostatistical estimation procedure is constructing the semivariogram. It is the most important step because the model chosen will be used throughout the process of kriging and will influence all results and conclusions [18]. Figure 5 presents the semivariogram and fitted model for $\mathrm{P}_{2} \mathrm{O}_{5} \%$.

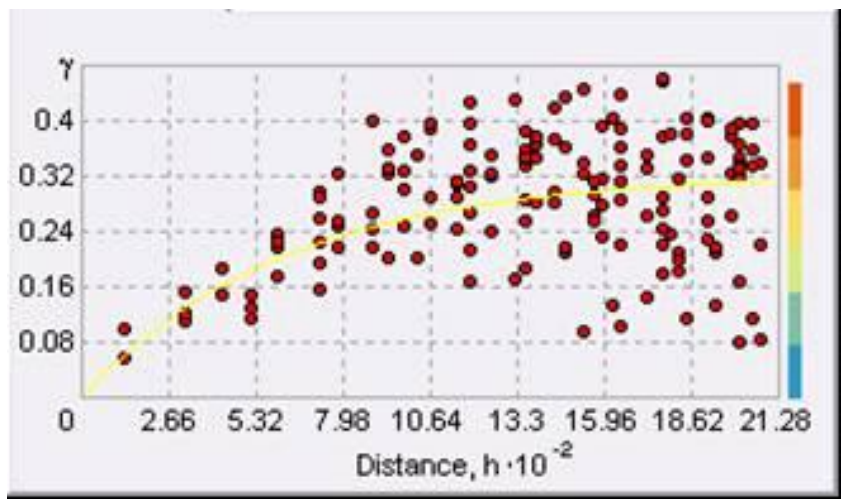

Figure 5: The semivariogram and fitted model for $\mathrm{P}_{2} \mathrm{O}_{5} \%$.

Nugget variance represents the experimental error and field variation within the minimum sampling spacing. The Nugget/Sill ratio can be regarded as a criterion to classify the spatial dependence of soil properties. If the ratio is less than $25 \%$, the variable has strong spatial dependence; between $25 \%$ and $75 \%$, the variable has moderate spatial dependence; and greater than $75 \%$, the variable shows only weak spatial dependence $[19,20]$. The attributes of the semivariogram for $\mathrm{P}_{2} \mathrm{O}_{5} \%$ were summarized in Table 2.

Table 2: Best fitted semivariogram model of $\mathrm{P}_{2} \mathrm{O}_{5} \%$.

\begin{tabular}{|l|l|}
\hline Parameters of variogram & \multicolumn{1}{|c|}{ Value } \\
\hline Type & Exponential \\
\hline Direction & Global \\
\hline Range, $m$ & 1852.3 \\
\hline Nugget effect $\left(\mathrm{C}_{0}\right)$ & Zero \\
\hline Sill $\left(\mathrm{C}+\mathrm{C}_{0}\right)$ & 0.32319 \\
\hline Large size & 210 \\
\hline Number of Lags & 10 \\
\hline
\end{tabular}


Table 2 inferred that the experimental error and field variation within the minimum sampling spacing because nugget variance equal to zero, also inferred that $\mathrm{P}_{2} \mathrm{O}_{5} \%$ has strong spatial dependence because the ratio $\left(\frac{C_{0}}{\left(C+C_{0}\right)}\right)$ is equal to Zero.

The best model is the one that has the standardized mean nearest to zero, the smallest root-mean-squared prediction error, the average standard error nearest the root-mean-squared prediction error, and the standardized root-mean-squared prediction error nearest to one [21]. The prediction errors of the indicator kriging estimates are given in Table 3.

Table 3: Prediction errors of Indicator Kriging.

\begin{tabular}{|l|l|}
\hline \multicolumn{1}{|c|}{ Prediction error } & \multicolumn{1}{c|}{ Value } \\
\hline Mean & 0.016 \\
\hline Root -mean-square & 0.400 \\
\hline Average standard error & 0.390 \\
\hline Mean standardized & 0.019 \\
\hline Root-mean-square standardized & 1.140 \\
\hline
\end{tabular}

The value of mean prediction error (0.016) being close to zero indicates that the predicted values are unbiased. Similar information is provided by the mean standardized prediction error (0.019). Also, the average standard error $(0.39)$ is nearest the root-mean-square of prediction errors (0.4). This shows that our model slightly over-estimates the variability of $\mathrm{P}_{2} \mathrm{O}_{5} \%$. The root-mean square prediction error (or kriging standard deviation) is a measure of the error that occurs when predicting data from point observations and provides the means for deriving confidence intervals for the predictions. Finally, the root-mean-square standardized (1.14) prediction error is very close to one, and thus corresponds to a very good fit between the point estimates of $\mathrm{P}_{2} \mathrm{O}_{5} \%$ and the geostatistical model using Indicator Kriging.

\section{Spatial Distribution}

Two areas in Qurayat area were compared because there are only four samples in the north of Qurayat area Y-18, U-18, U-22 and U-26 which have low $\mathrm{P}_{2} \mathrm{O}_{5} \% 17.28$, $17,19.61$ and 21.54 respectively. Thus, four samples will be used in first area and not used in the second area (Figure 6), then the effect of these samples will be studied on the two areas.

Indicator Kriging was used to interpolate the unknown locations, the prediction map is displayed with relative colours as well as probability map and other layers were posted using the power of GIS. These layers have boundaries of Dakhla Formation, $\mathrm{Cr} 2 \mathrm{dh} 1$ and three faults distributed in North and South of the area. The results are displayed in the following maps (Figure 7).

It has been decided to map $\mathrm{P}_{2} \mathrm{O}_{5} \%$ with threshold $25.45 \%$ and use indicator kriging in the following cases:

- Examine the prediction at the northern part using all the samples including the 4 scattered samples at the northern area. 
- Examine the prediction at the same area without taking the 4 samples; prediction has been carried out based on the southern samples only.

- Provide the case of mapping the well sampled part only, in this case; the northern part is considered negligible or with zero $\mathrm{P}_{2} \mathrm{O}_{5} \%$.

Figure 8 reveals the influence of sampling number and its distribution and how it is possible to mislead the decision maker when an area with poor samples is taken as part of the well sampled area. Figure 8(a) shows this case using the effect of four samples. Those samples were taken at the northern part of the study area.

Results of step 1 can be seen in Figures 8(a). However, Figures 8(b) and, 8(c) show the results of steps 2 and 3 respectively. When the four samples were considered, the interpolation process performs depending on the over all samples Figure 7(c) so, the northern area of the same figure has the yellow colour that has a probability range from 0 to 0.2 . Nevertheless, when the four samples were removed, the interpolation process performs depending only on the southern samples. It can be noted that the northern area in Figure $\mathbf{7}$ (d) has three different colours approximately that have the first three probabilities ranges, $(0-0.2),(0.2-0.4)$ and (0.4-0.6). This difference between the two cases because of the interpolation process of obtaining a value for the variable of interest at an unsampled location is based on the surrounding measurements. However, in this particular case, removing the four samples does not affect the southern area but only the northern part of the area. One should note that extending the mining area should be based on sufficient sampling points so that a reliable prediction of the grade distribution at the entire Qurayat area could reach satisfaction results.

Finally, one could see the impact of considering the four samples in the calculations of the production maps. The effect appears clearly in the northern part of the area, above Dakhla Formation boundaries, but in the southern area the effect is limited.

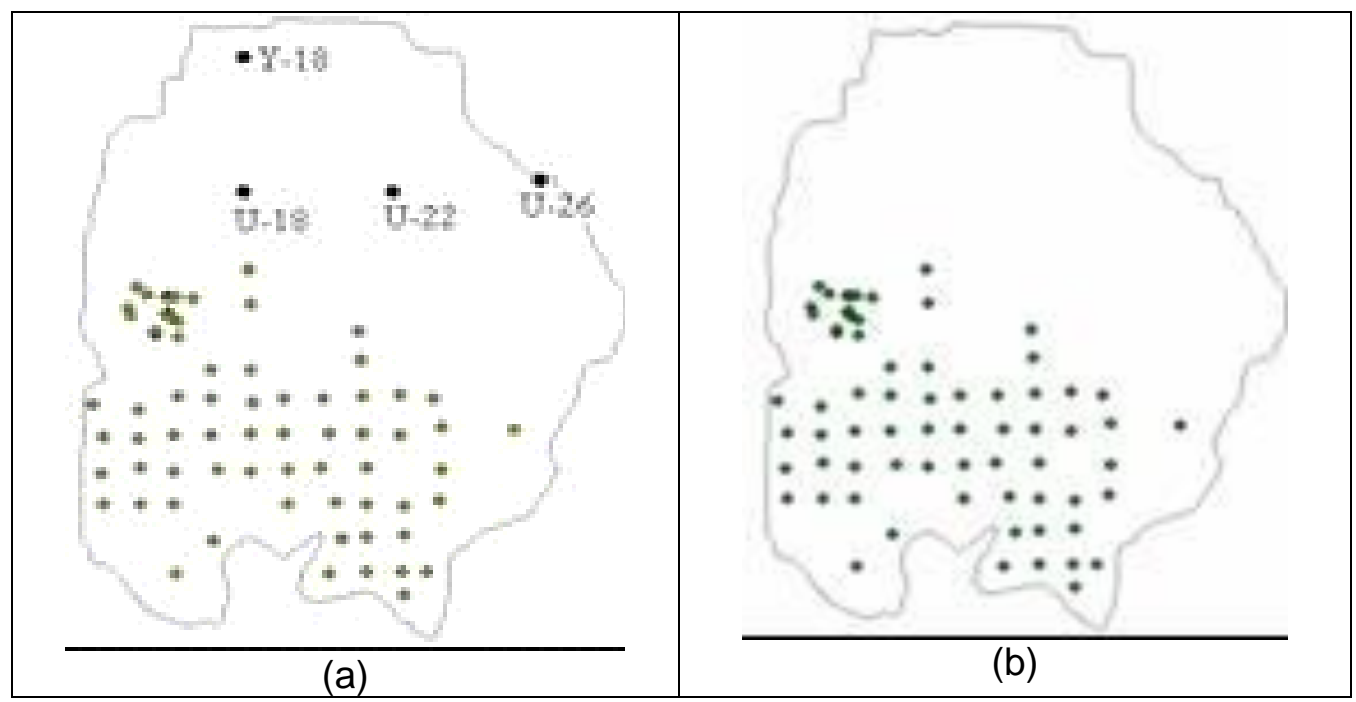

Figure 6: (a) Overall data, and (b) without the excluded 4 samples. 


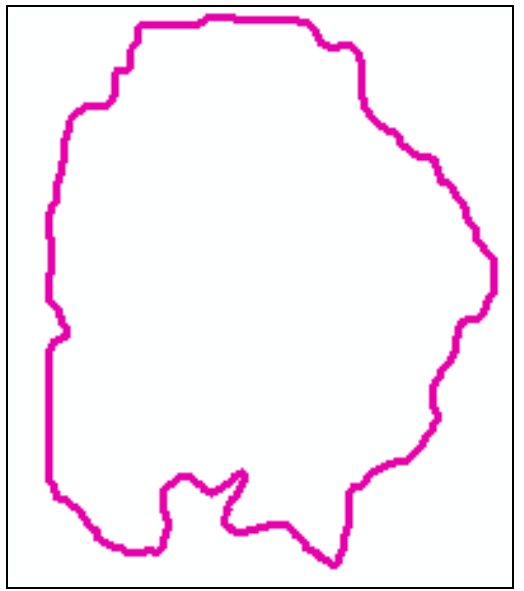

Qurayat boundaries

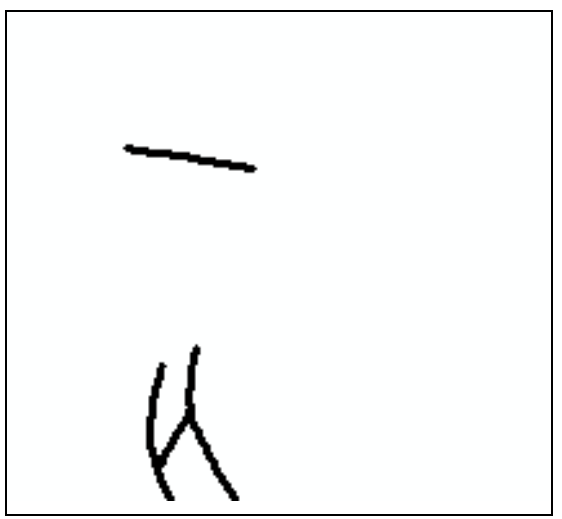

Faults

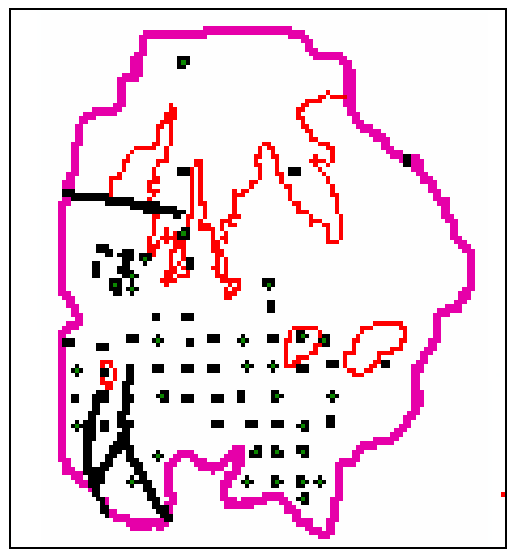

Combination of geographic data

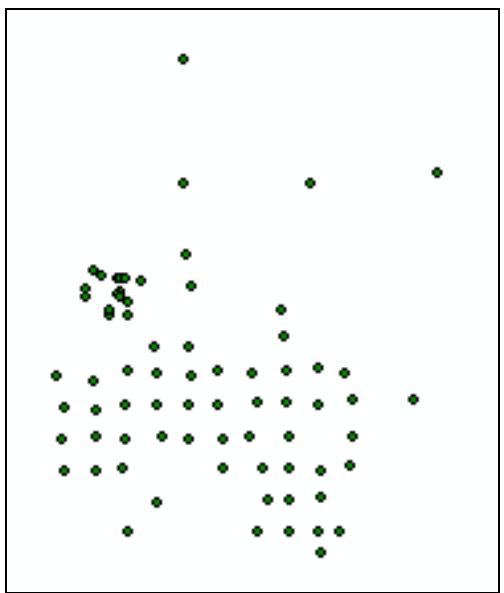

Sampling points
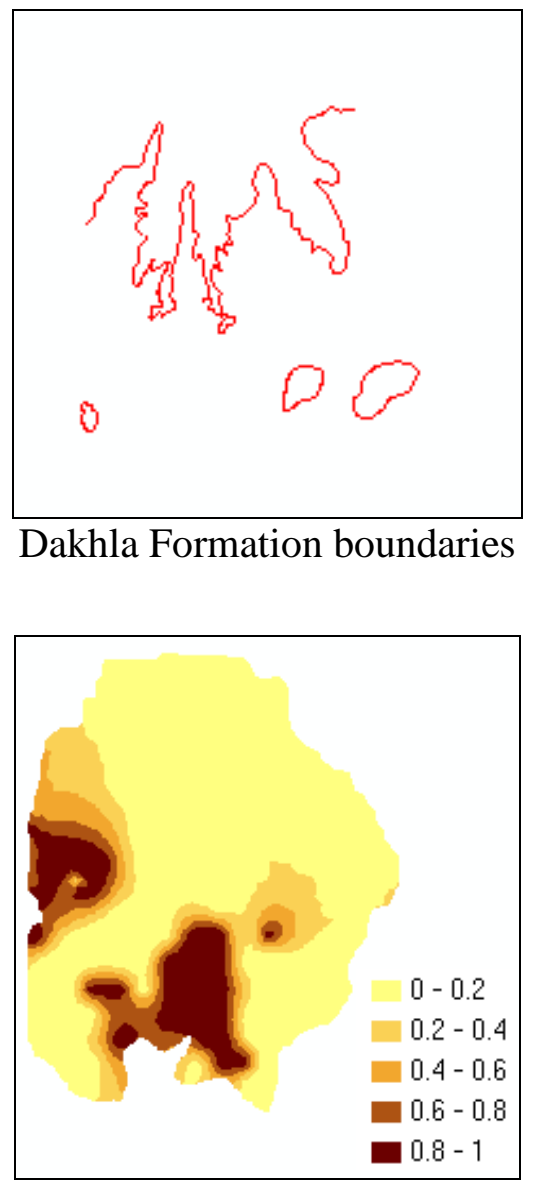

Prediction map

Figure 7: Different maps representing the input layers to GIS at Qurayat area. 


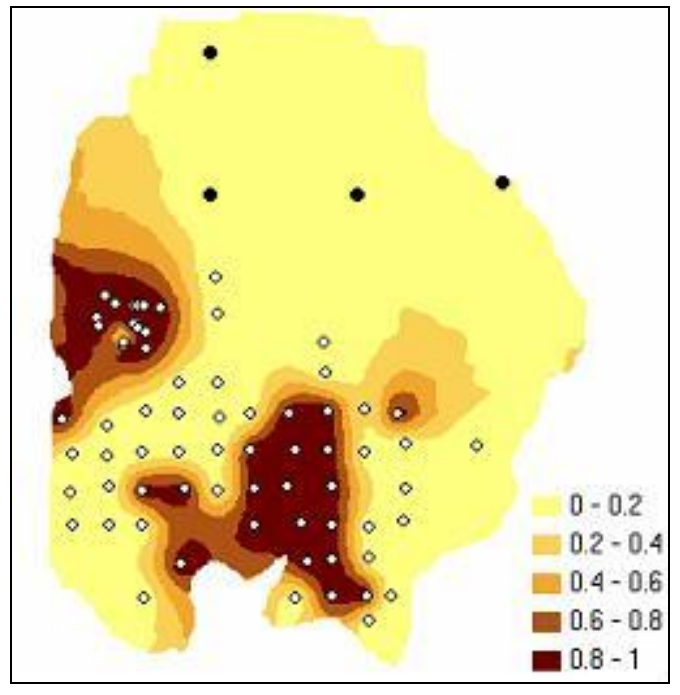

(a)

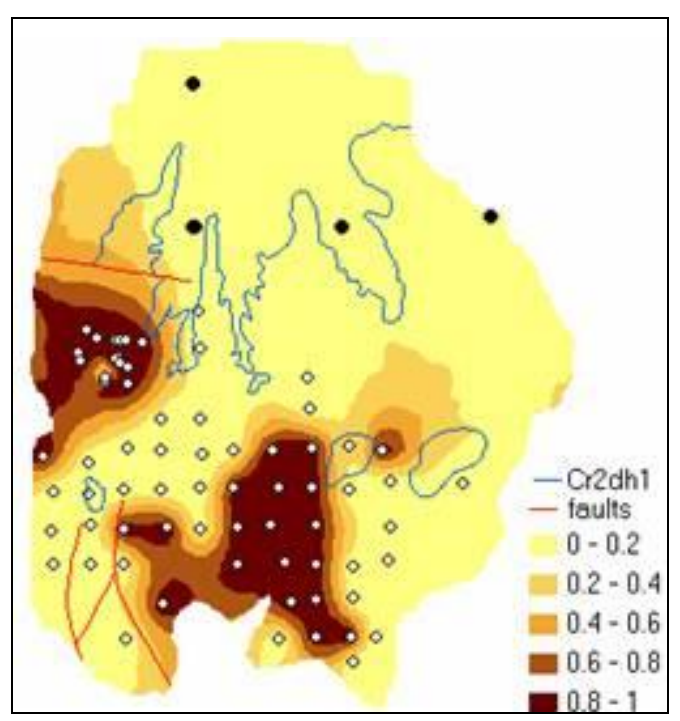

(c)

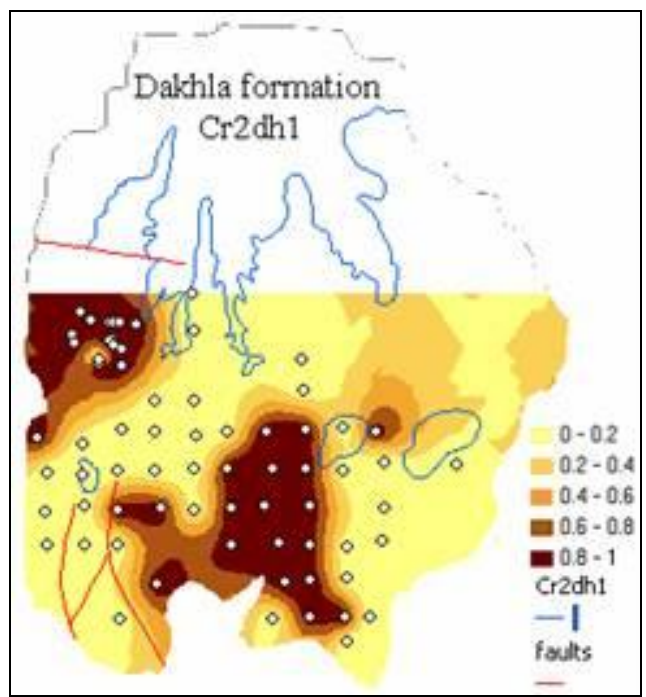

(b)

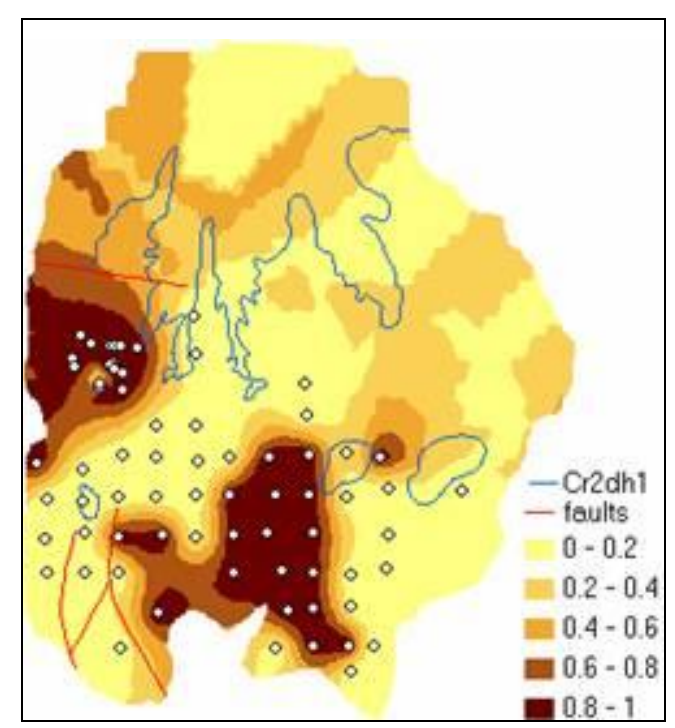

(d)

Figure 8: Prediction map of $\mathrm{P}_{2} \mathrm{O}_{5} \%,\{(\mathrm{a}),(\mathrm{c})\}$ for the first area \& $\{(\mathrm{b}),(\mathrm{d})\}$ for the second area.

\section{CONCLUSIONS}

An integrated methodology using indicator kriging and GIS has been introduced and implemented over part of El Mahamid area (Qurayat area) to demonstrate the possibility of using the methodology in mapping the spatial distribution of $\mathrm{P}_{2} \mathrm{O}_{5} \%$ at certain mining area. IK was used to differentiate between the 
areas with economical mining grades of phosphate and poor ones. In addition, GIS was used to support the visualization of the results and add more information to the kriged results. Such mix would enhance and reveal the other mining parameters that should be taken into consideration for better management and plan the mining activities at the study area.

\section{ACKNOLEDGEMENT}

The authors would like to thank the Egyptian Mineral Resources Authority (EMRA) and the people at El Nasr Phosphate Co., for their co-operation and providing the data used throughout this work.

\section{REFERENCES}

[1] Said, R. (1968): "Report on the results of Geological Exploration at The El Mahamid Phosphorite Deposit carried out in 1966-1968”, Egyptian General Organization for Geological Research and Mining, pp. 154-173.

[2] Abbady, A.G.E., Uosif, M.A.M., and El-Taher, A., (2005): "Natural radioactivity and dose assessment for phosphate rocks from Wadi El-Mashash and ElMahamid Mines, Egypt", Journal of Environmental Radioactivity, 84, (2005), pp. 65-78.

[3] Abu Ali, M.H., (1987): "Beneficiation of Abu-Tartur phosphate ore with special reference to the minimization of water consumption". MSc. thesis, Mining \& Metallurgical Engineering Department, Faculty of Engineering, Assiut University, Egypt.

[4] Ahmed, S.S., Rashad, M.Z., and El Tahlawi, M.R., (2005): "Geostatistics as a usual technique for monitoring the changes in the water quality parameters", The $9^{\text {th }}$ international Mining, Petroleum, and Metallurgical Engineering Conference, Cairo University. Feb. 2005.

[5] Rashad, M.Z. and Ibrahim, A.R., (1985): "Application of some Geostatistical methods to evaluate phosphate deposit (Abu-Tartur Area, Egypt)", Bulletin of the Faculty of Engineering, Vol. 13, part 1, Jan. 1985, pp. 77-89.

[6] Krivoruchko, K., and. Gotway, C.A., (2004): "Creating Exposure Maps Using Kriging", Public Health GIS News and Information.

[7] Lloyd, C.D., and Atkinson, P.M., (2004): "Increased accuracy of geostatistical prediction of nitrogen dioxide in the United Kingdom with secondary data", International Journal of Applied Earth Observation and Geo-information, 5 (2004), pp. 293-305.

[8] Taboada, J., Vaamonde, A., Saavedra, A., and Ordóñez, C., (2002): "Geostatistical study of the feldspar content and quality of a granite deposit", Engineering Geology 65, pp. 285-292.

[9] Keogh, A.J., and Moulton, C., (1998):"Median Indicator Kriging - A case study in iron ore", Proceedings of a one day Symposium: Beyond Ordinary Kriging. October $30^{\text {th }}$, 1998, Pert, Western Australia. Geostatistical Association of Australia, pp. 106-120.

[10] Liu, X., Wu J., and Xu, J., (2005): "Characterizing the risk assessment of heavy metals and sampling uncertainty analysis in paddy field by geostatistics and GIS", Environmental Pollution, pp. 1-8. 
[11] Potoglou, D., and Kanaroglou, P.S., (2005): "Carbon monoxide emissions from passenger vehicles: predictive mapping with an application to Hamilton, Canada", Transportation Research Part D 10 (2005), pp. 97-109.

[12] Diodato, N., and Ceccarelli, M., (2004): "Multivariate indicator Kriging approach using a GIS to classify soil degradation for Mediterranean agricultural lands", Ecological Indicators 4, pp. 177-187.

[13] Tsanis, I.K., and Gad, M.A., (2000): "A GIS precipitation method for analysis of storm kinematics", Environmental Modelling \& Software 16 (2001), pp. 273281.

[14] Watson, W.D., Ruppert, L.F., Bragg, L.J., and Tewalt, S.J., (2001): "A geostatistical approach to predicting sulfur content in the Pittsburgh coal bed", International Journal of Coal Geology, Vol. 48, pp. 1-22.

[15] Wackernagel, H., (1995): "Multivariate geostatistics: an introduction with applications", Springer- Verlag Berlin, Heidelberg, Germany.

[16] Royle, A.G., (1992): "A personal overview of geostatistics", Geological Society Special Publication No. 63, pp. 233-241.

[17] Remote Sensing Centre, Academy of Scientific Research and Technology, (1990),"Space Atlas of Egypt", first edition, Vol. 2, page 49.

[18] Clark, I., (1979): "The Semi-Variogram-Part 1", Eng. and Min. Journal, July.

[19] Chang, Y.H., Scrimshaw, M.D., Emmerson, R.H.C., and Lester, J.N., (1998): Geostatistical analysis of sampling uncertainty at the Tollesbury managed retreat site in Blackwater Estuary, Essex, UK: Kriging and Cokriging approach to minimise sampling density. Sci., Total Environ., 221, pp. 43-57.

[20] Chien, Y.L., Lee, D.Y., Guo, H.Y., and Houng, K.H., (1997): "Geostatistical analysis of soil properties of mid-west Taiwan soils, Soil Sci., 162, pp. 291-297.

[21] An ESRI ${ }^{\circledR}$ White Paper, (2001): "ArcGISTM Geostatistical Analyst: Powerful Exploration and Data Interpolation Solutions", March, USA.

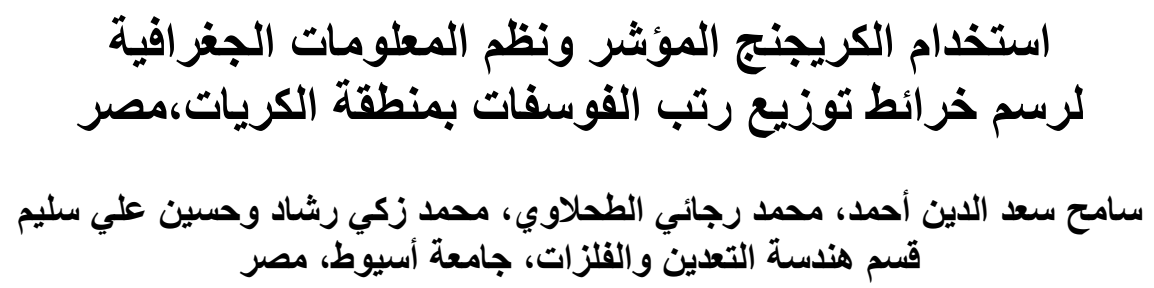

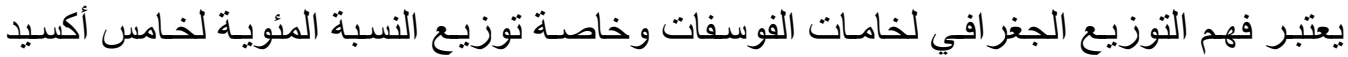

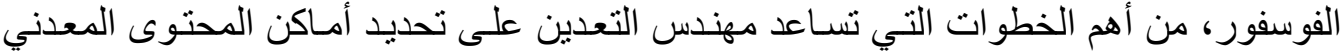

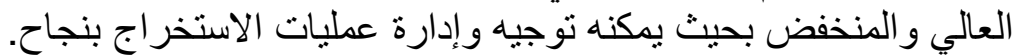

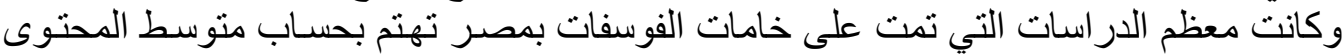

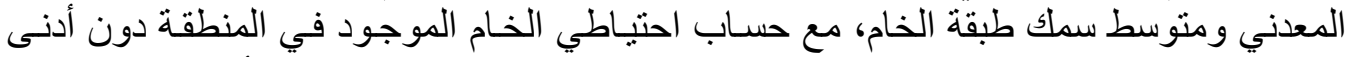

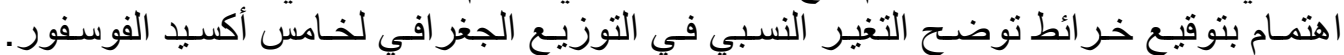
ناهيك عن استخدام الطرق التقليدية في الحسابات. 


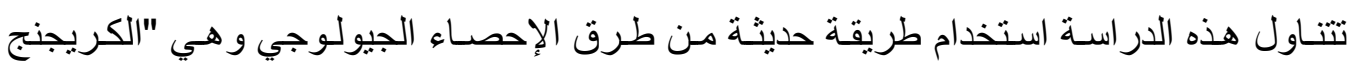

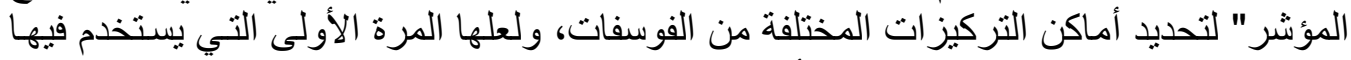

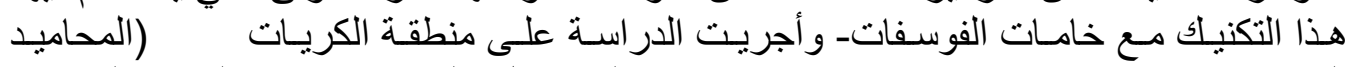

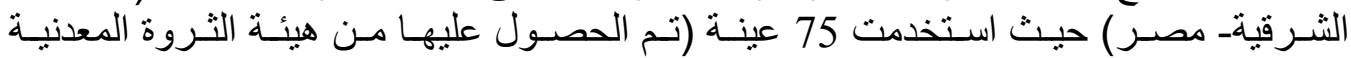
المصرية) معلومة الإحداثيات والمحتوى المعدني من

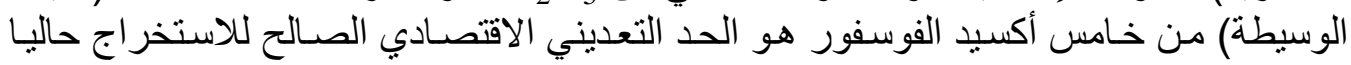
وتم در اسة التوزيع للخام في المنطقة.

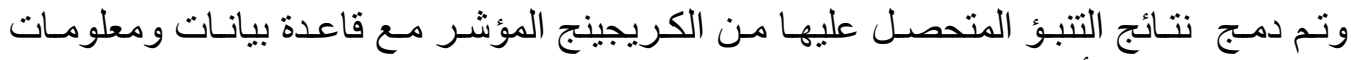

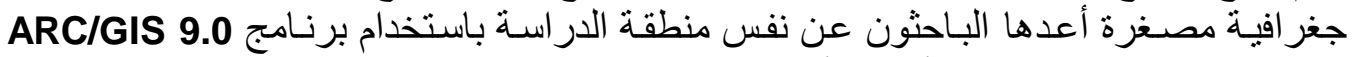

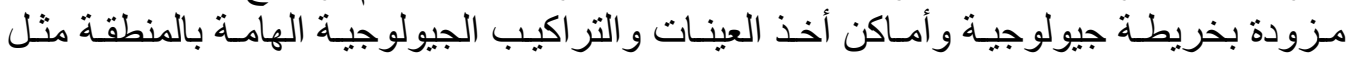

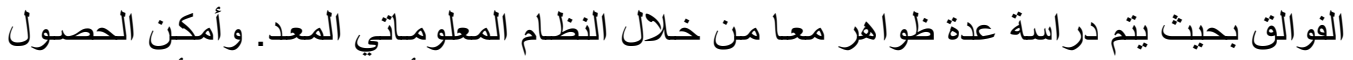

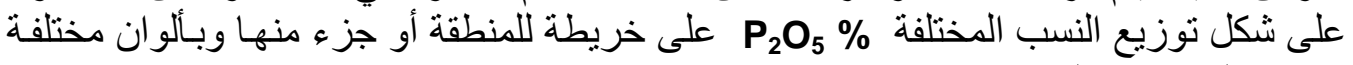
توضح التباين في التوزيع.

إن إعداد مثل هذه الخر ائط سوف يسـاعد مهندس التعدين علي اتخـاذ القرارات السليمة المؤديـة

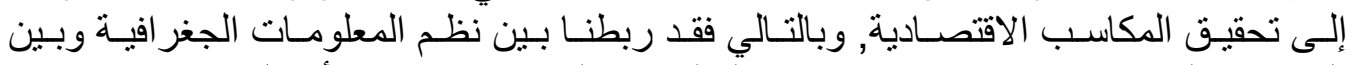

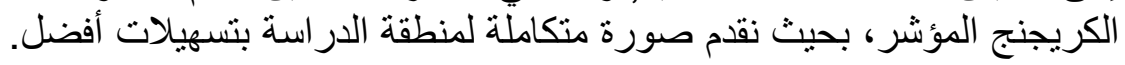

